\title{
New Design and Injection Molding Analysis of a Low Smoke Zero Halogen Cable Trunk
}

\author{
Xiaoxun Zhang ${ }^{1}$, Fang $\mathrm{Ma}^{2} \&$ Xia $\mathrm{Li}^{1}$ \\ ${ }^{1}$ School of Materials Engineering, Shanghai University of Engineering Science, Shanghai, China \\ ${ }^{2}$ College of Automotive Engineering, Shanghai University of Engineering Science, Shanghai, China \\ Correspondence: Xiaoxun Zhang, School of Materials Engineering, Shanghai University of Engineering Science, \\ 333 Longteng Road, Songjiang District, Shanghai 201620, China. Tel: 86-21-67-791-202. E-mail: \\ xx.zhang.cn@gmail.com
}

Received: August 2, 2012 Accepted: September 6, 2012 Online Published: September 21, 2012

doi:10.5539/ijc.v4n5p48 URL: http://dx.doi.org/10.5539/ijc.v4n5p48

\begin{abstract}
The traditional production process of a cable trunk is plastic extrusion with PVC or other halogen containing materials. However, they have many disadvantages such as easy burning, producing toxic gases and smokes. A low smoke zero halogen (LSZH) cable trunk was designed and developed in the present study and the injection molding process was adopted to produce the LSZH cable trunk. Numerical simulations were applied to investigate the effects of the important process parameters on the warpage of the cable trunk. Comparing the simulation results under different process conditions and consideration both of the volumetric shrinkage and the total warpage displacement, it is found that the process parameters, including mold temperature $75^{\circ} \mathrm{C}$, melt temperature $265^{\circ} \mathrm{C}$, injection pressure $190 \mathrm{MPa}$, packing pressure $152 \mathrm{MPa}$, cooling water temperature $50^{\circ} \mathrm{C}$ and injection time $3 \mathrm{~s}$, are the optimal process conditions for the injection molding process of the new designed cable trunk.
\end{abstract}

Keywords: design, injection molding, numerical simulation, low smoke zero halogen (LSZH), cable trunk

\section{Introduction}

A cable trunking system is defined as a system of enclosures consisting of slotted trunking lengths and other appropriate system components intended for the accommodation and, where necessary, for the segregation of conductors, insulated cables or cords in a cabinet. The components of a slotted cable trunking system include a) slotted trunking length, b) trunking fitting, c) fixing device and d) system accessory. The slotted trunking length is the main component of a slotted cable trunking system comprising of a cable trunk with slotted walls and one or more covers which may be opened or removed.

The traditional cable trunk is long and the traditional production process is plastic extrusion with PVC or other halogen containing materials. However, they have many disadvantages such as easy burning, producing toxic gases and smokes. With the improvement of the people's living standard and the ever-complicated structure of industrial and commercial building where high flexibility is demanded, more and more attention is payed to the safety and environmental compatibility of the wires and cables used for integrated wiring.

The low smoke zero halogen (LSZH) materials, its production technology and its application in the cable industry have been investigated for decades to meet the needs of safety and environmental compatibility (Chaudhry et al., 1998; Cross et al., 2003; Hull et al., 2008; Naskar et al., 2007). Cross et al. (2003) found that Zinc hydroxystannate (ZHS) is an effective partial replacement for the conventional hydrated fire-retardant fillers alumina trihydrate (ATH) and magnesium hydroxide (MH) when incorporated into a halogen-free EVA cable compound. Naskar et al. (2007) developed the thin-walled halogen-free cable insulation and thin-walled halogen-free fire-resistant low-smoke cable sheathing compounds based on polyolefin elastomer and ethylene vinyl acetate (EVA) blends.

One of the most important quality problems of injection molded plastic parts is warpage (Ahmad et al., 2009). The direct cause of warpage is the uneven shrinkage, which results in internal stress and residual stress (Ahmad et al., 2009; Erzurumlu \& Ozcelik, 2006). Warpage appears when these stresses exceed the stiffness of the material (Jiang et al., 2010). The accurate prediction of warpage of injection molded parts is important to achieve 
successful mold design with high precision (Huang et al., 2009; Tang et al., 2007). In the present study, the traditional extruded cable trunk was designed to an injection molded LSZH cable trunk. PC/ABS polymer alloy Multilon TN-7500 was adopted as the material of the cable trunk. Using the software package Moldflow, numerical simulations of the injection molding process of the cable trunk were conducted under different processing conditions. The volumetric shrinkage warpage and the total warpage displacements were calculated and compared to find the optimal process conditions for the cable trunk.

\section{Traditional Design of the Cable Trunk}

The traditional design of a cable trunk is shown in Figure 1. The traditional production process of the cable trunk is plastic extrusion with PVC or other halogen containing materials. They have many disadvantages such as easy burning, producing toxic gases and smokes.

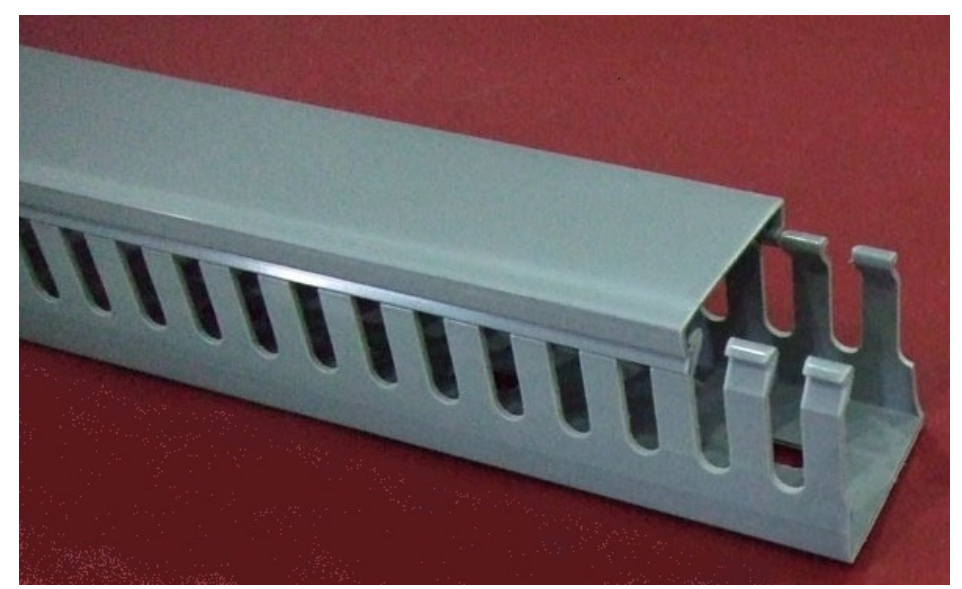

Figure 1. The traditional cable trunk

\section{New Design of the LSZH Cable Trunk}

\subsection{Structures and Materials}

The structure of the new designed cable trunk is shown in Figure 2. There is one row of holes in the base of the cable trunk. A round small hole is located in the center and two square holes are located near the corresponding end of the cable trunk. Four holes are designed for installation near the four corners in the base of the cable trunk. The wall of the cable trunk is slotted with openings allowing cables to pass through. The openings can be with open or closed boundary and may have different shapes, normally designed to maintain wiring in position. The slotted cable trunking systems shall be so designed and constructed that where required they ensure reliable support, accommodation and segregation of the insulated conductors and/or cables contained therein.

PC/ABS polymer alloy Multilon TN-7500 developed by Teijin Chemicals Ltd., which is often used in electrical and electronic appliance parts, lighting fixtures, precision machinery parts, automobile parts, housewares and a wide variety of other applications, is adopted as the material of the cable trunk. 

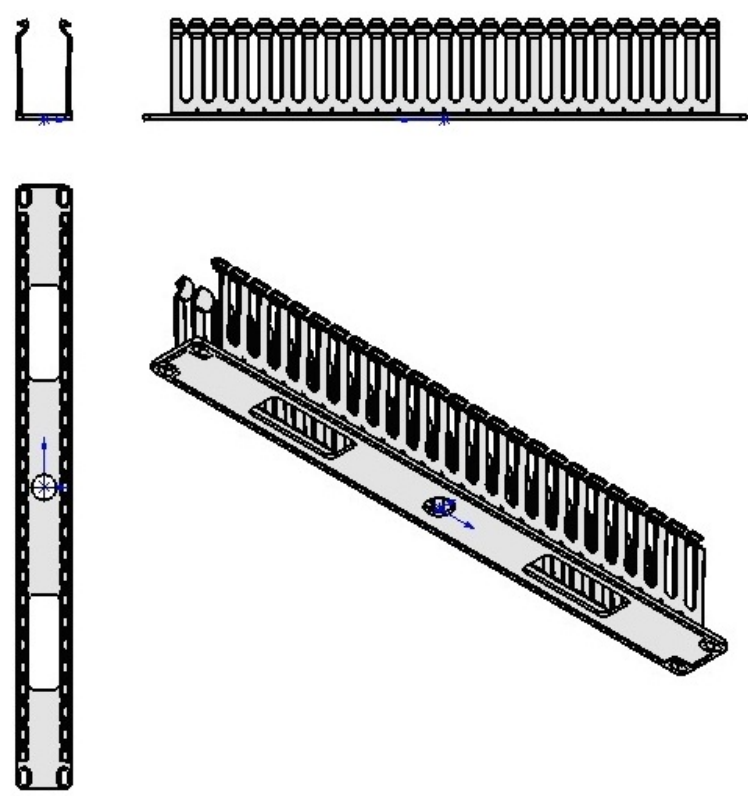

Figure 2. New design of the cable trunk

\subsection{Injection Molding Process}

Injection molding process is adopted to produce the new designed cable trunk. Injection molding is widely used for manufacturing a variety of parts, from the smallest component to entire body panels of cars. Injection molding is a manufacturing process for producing parts from both thermoplastic and thermosetting plastic materials. Material is fed into a heated barrel, mixed, and forced into a mold cavity where it cools and hardens to the configuration of the cavity. After a product is designed, molds are made by a moldmaker from metal and precision-machined to form the features of the desired part. The shape and structure of the cable trunk, the runner system and the cooling channels are designed and shown in Figure 3.

The recommended process parameters which provided in the library of Moldflow material database for injection molding of Multilon TN-7500 are as follows: drying temperature $80^{\circ} \mathrm{C}$, drying time $5 \sim 8 \mathrm{~h}$, melt temperature $230 \sim 270^{\circ} \mathrm{C}$, mold temperature $50 \sim 60^{\circ} \mathrm{C}$, injection pressure $59 \sim 147 \mathrm{MPa}$.

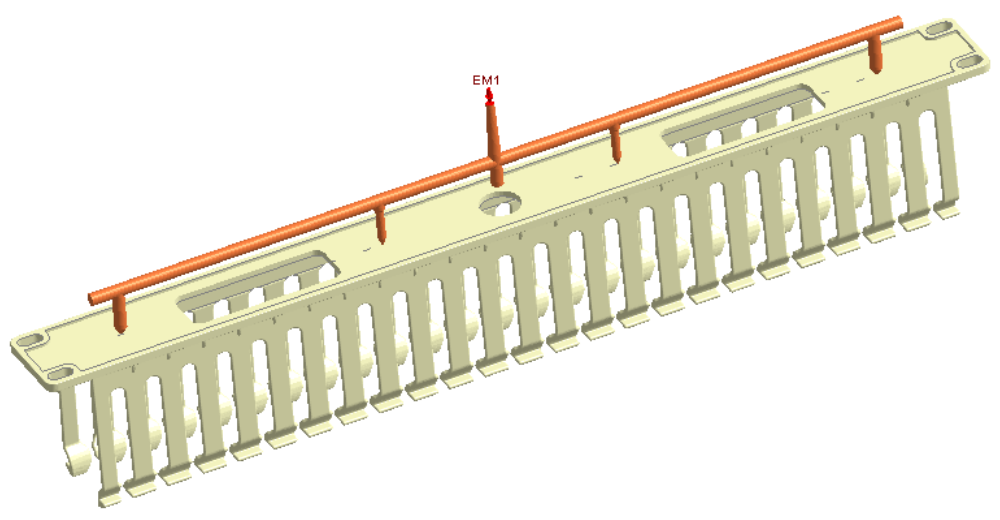

Figure 3. The model for injection molding of the cable trunk

\section{Numerical Analysis of the Injection Molding Process of the LSZH Cable Trunk}

\subsection{Numerical Analysis of the Injection Molding Process}

Numerical simulations of the injection molding process of the LSZH cable trunk are performed using Moldflow software platform. Based on the Moldflow softwarepackage, the gate, the primary runner and the sub-runner are established on the cable trunk. The size of the primary runner is $6 \mathrm{~mm}$ in diameter and $15 \mathrm{~mm}$ in length. The diameter of the sub-runner is $4 \mathrm{~mm}$ and the diameter of the gate is $1 \mathrm{~mm}$. After modeling is complete, the meshes 
of the runner system and the cable trunk are carried out.

In order to find the optimal process parameters, many study cases were implemented and the injection molding conditions were shown in Table 1. Note that the packing pressure was calculated from the percentage of the maximum injection pressure. Other injection molding parameters were set as follows: mold temperature is $75^{\circ} \mathrm{C}$, maximum injection pressure is $190 \mathrm{MPa}$, injection time is $3 \mathrm{~s}$, packing time is $10 \mathrm{~s}$, and the ejection time is $5 \mathrm{~s}$.

Table 1. Injection molding parameters of the LSZH cable trunk

\begin{tabular}{cccc}
\hline Case No. & Cooling water temperature $\left({ }^{\circ} \mathrm{C}\right)$ & Melt temperature $\left({ }^{\circ} \mathrm{C}\right)$ & Packing pressure $(\%)$ \\
\hline 1 & 25 & 265 & 80 \\
2 & 50 & 265 & 100 \\
3 & 50 & 300 & 80 \\
4 & 50 & 265 & 80 \\
5 & 50 & 265 & 60 \\
\hline
\end{tabular}

\subsection{Effects of Process Conditions on the Warpage}

Using the software package Moldflow, numerical simulations of the injection molding process of the cable trunk were conducted under the processing conditions shown in Table 1. The volumetric shrinkage warpage and the total warpage displacements (all effects are considered) were calculated and compared to find the optimal process conditions for the cable trunk.

The simulation results of Case 1 are shown in Figure 4. The volumetric shrinkage warpage is from $0.7366 \%$ to $11.21 \%$ and the volumetric shrinkage at most of the cable trunk is about $0.74 \%$. The total warpage displacement is from $0.0571 \mathrm{~mm}$ to $4.061 \mathrm{~mm}$. The simulation results of Case 2 are shown in Figure 5. The volumetric shrinkage warpage is from $0.6467 \%$ to $11.17 \%$ and the volumetric shrinkage at most of the cable trunk is about $0.65 \%$. The total warpage displacement is from $0.0861 \mathrm{~mm}$ to $3.817 \mathrm{~mm}$. The simulation results of Case 3 are shown in Figure 6. The volumetric shrinkage warpage is from $1.313 \%$ to $13.5 \%$ and the volumetric shrinkage at most of the cable trunk is about $1.3 \%$. The total warpage displacement is from $0.0177 \mathrm{~mm}$ to $3.549 \mathrm{~mm}$. The simulation results of Case 4 are shown in Figure 7 . The volumetric shrinkage warpage is from $0.9168 \%$ to $11.39 \%$ and the volumetric shrinkage at most of the cable trunk is about $0.92 \%$. The total warpage displacement is from $0.0585 \mathrm{~mm}$ to $3.539 \mathrm{~mm}$. The simulation results of Case 5 are shown in Figure 8 . The volumetric shrinkage warpage is from $1.194 \%$ to $11.52 \%$ and the volumetric shrinkage at most of the cable trunk is about $1.2 \%$. The total warpage displacement is from $0.0292 \mathrm{~mm}$ to $3.358 \mathrm{~mm}$.

Comparing the simulation results of Cases No.1 to No.5, it can be seen from Figure 4 to Figure 8 that: (1) the total warpage displacement of Case 1 is the largest and that of Case 5 is the smallest. The total warpage displacements of Case 1 and Case 2 are larger than those of Case 3, Case 4 and Case 5. From a point of view to reduce the total warpage displacement, the process conditions of Case 3, Case 4 and Case 5 are better than those of Case 1 and Case 2. (2) The volumetric shrinkage of Case 3 is the largest and that of Case 2 is the smallest. The volumetric shrinkages of Case 3 and Case 5 are larger than those of Case 1, Case 2 and Case 4. From a point of view to reduce the volumetric shrinkage, the process conditions of Case 1, Case 2 and Case 4 are better than those of Case 3 and Case 5. Consideration both of the volumetric shrinkage and the total warpage displacement, it is found that the process parameter of Case 4 is the optimal process condition for the injection molding process of the new designed cable trunk. 


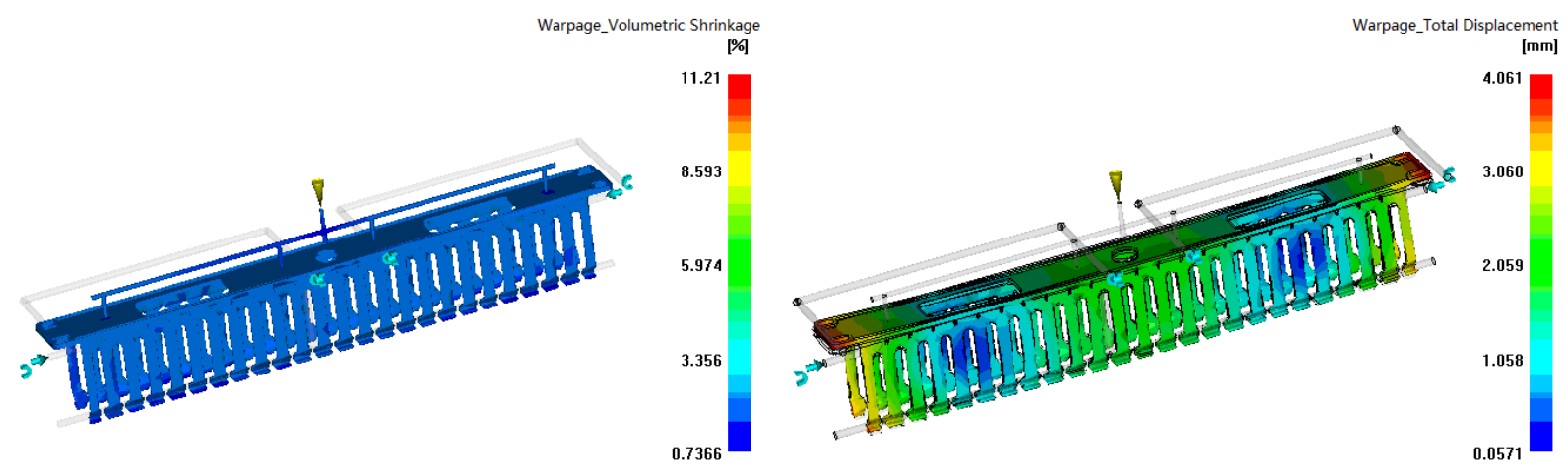

Figure 4. The warpage of the injection molded cable trunk in Case No.1

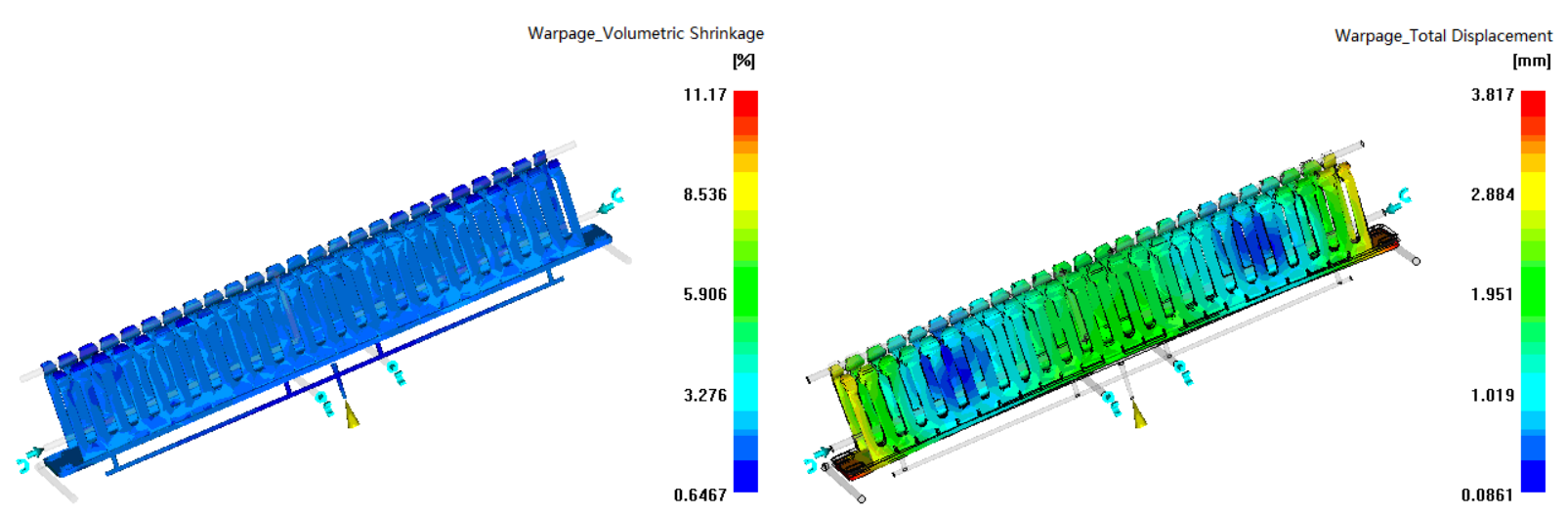

Figure 5. The warpage of the injection molded cable trunk in Case No.2

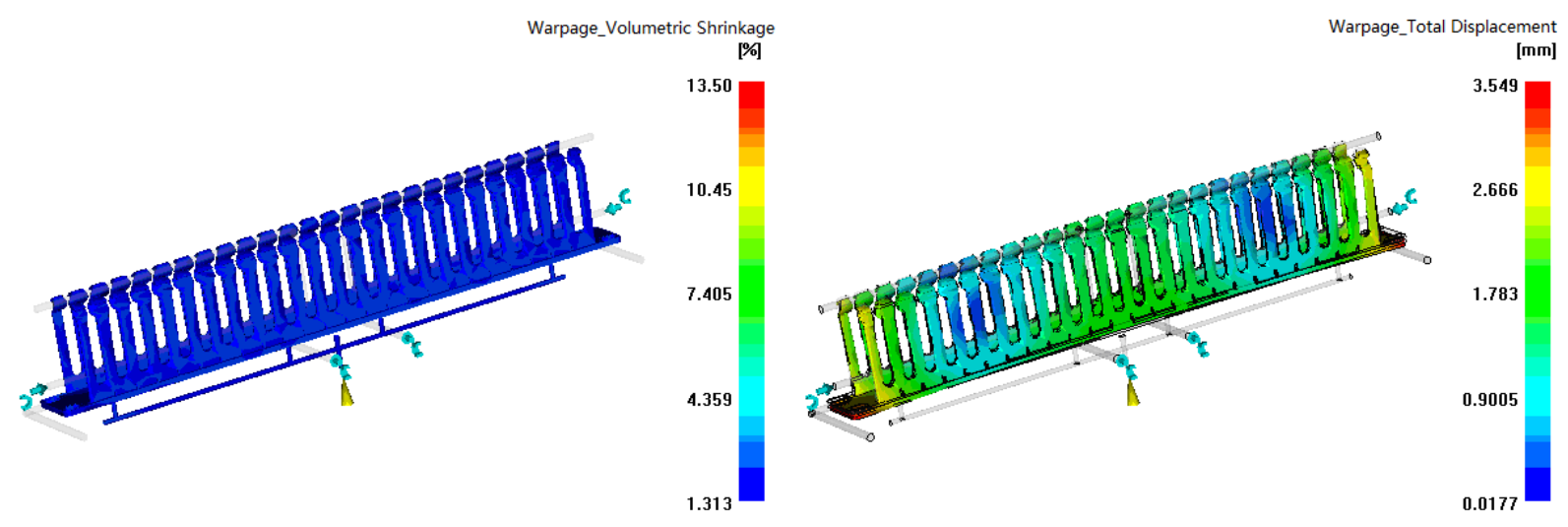

Figure 6. The warpage of the injection molded cable trunk in Case No.3 


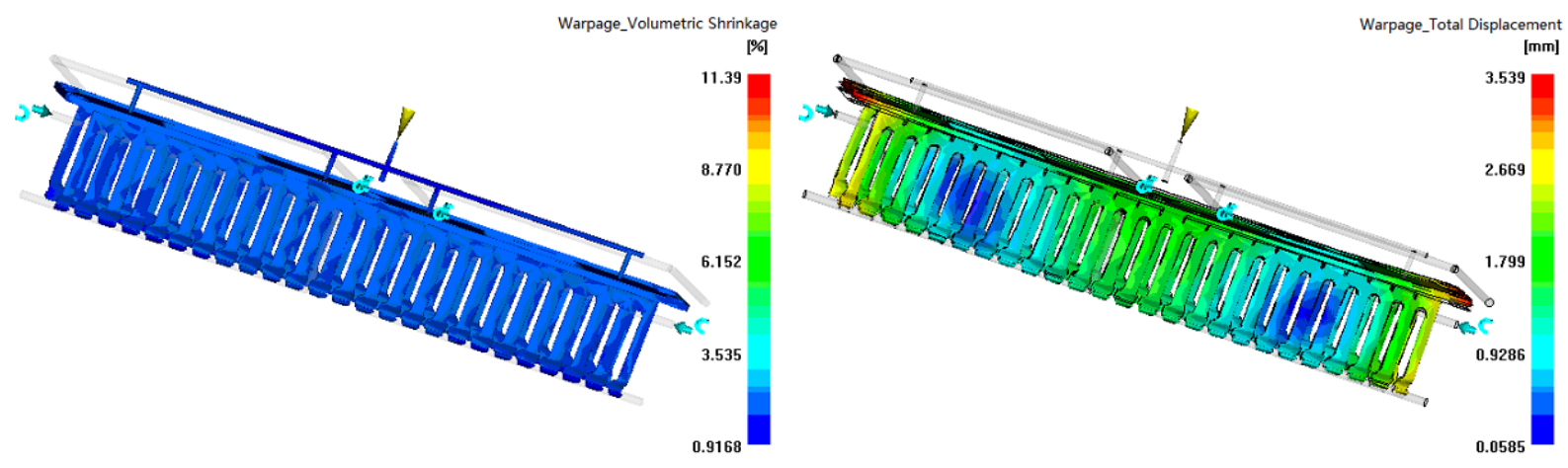

Figure 7. The warpage of the injection molded cable trunk in Case No.4

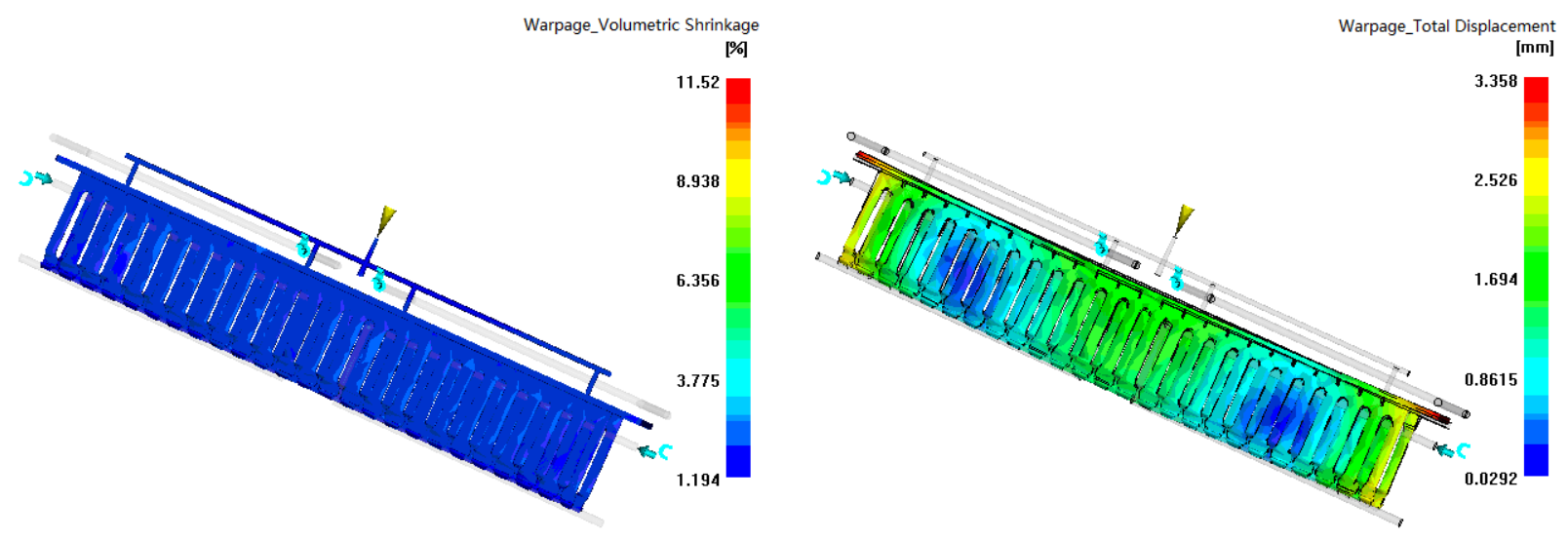

Figure 8. The warpage of the injection molded cable trunk in Case No.5

\section{Conclusions}

The traditional extruded cable trunk was designed to an injection molded LSZH cable trunk in this study. PC/ABS polymer alloy Multilon TN-7500 was adopted as the material of the cable trunk. Using the software package Moldflow, numerical simulations of the injection molding process of the cable trunk were conducted under different processing conditions. The volumetric shrinkage warpage and the total warpage displacements (all effects are considered) were calculated and compared to find the optimal process conditions for the cable trunk. Comparing the simulation results under different process conditions and consideration both of the volumetric shrinkage and the total warpage displacement, it is found that the process parameters, including mold temperature $75^{\circ} \mathrm{C}$, melt temperature $265^{\circ} \mathrm{C}$, injection pressure $190 \mathrm{MPa}$, packing pressure $152 \mathrm{MPa}$, cooling water temperature $50^{\circ} \mathrm{C}$ and injection time $3 \mathrm{~s}$, are the optimal process conditions for the injection molding process of the new designed cable trunk.

\section{Acknowledgements}

This work is supported by Shanghai Leading Academic Discipline Project under grant J51402 and supported by Innovation Program of Shanghai Municipal Education Commission under grant $12 Z Z 183$ and supported by Science Foundation for the Excellent Youth Scholars of Shanghai Municipal Education Commission under grant gjd10008.

\section{References}

Ahmad, A. H., Leman, Z., \& Azmir, M. A. (2009). Optimization of warpage defect in injection moulding process using ABS material. In IEEE Int. Conf. on Modelling \& Simulation (pp. 470-474), Bali, Indonesia, 25-29 May 2009. http://dx.doi.org/10.1109/AMS.2009.120

Chaudhry, B. I., Hage, E., \& Pessan, L. A. (1998). Effects of processing conditions on the phase morphology of PC/ABS polymer blends. Journal of Applied Polymer Science, 67(9), 1605-1613. http://dx.doi.org/10.1002/(SICI)1097-4628(19980228)67:9<1605::AID-APP12>3.0.CO;2-T

Cross, M. S., Cusack, P. A., \& Hornsby, P. R. (2003). Effects of tin additives on the flammability and smoke 
emission characteristics of halogen-free ethylene-vinyl acetate copolymer. Polymer Degradation and Stability, 79(2), 309-318. http://dx.doi.org/10.1016/S0141-3910(02)00294-X

Erzurumlu, T., \& Ozcelik, B. (2006). Minimization of warpage and sink index in injection-molded thermoplastic parts using Taguchi optimization method. Materials \& Design, 27(10), 853-861. http://dx.doi.org/10.1016/j.matdes.2005.03.017

Huang, G., Li, X., Wu, X., \& Li, J. (2009). Optimized design of injection mould for mobile phone front shell based on CAE technology. In IEEE Int. Conf. on Artificial Intelligence (pp. 648-650), SanYa, China, 25-26 April 2009. http://dx.doi.org/10.1109/JCAI.2009.218

Hull, T. R., Lebek, K., Pezzani, M., \& Messa, S. (2008). Comparison of toxic product yields of burning cables in bench and large-scale experiments. Fire Safety Journal, 43(2), 140-150. http://dx.doi.org/10.1016/j.firesaf.2007.06.004

Jiang, Z., Liu, X., \& Bu, J. (2010). Modeling, analysis, and simulation of soldering process for FPC connector. Advanced Materials Research, 154-155, 643-646. http://dx.doi.org/10.4028/www.scientific.net/AMR.154-155.643

Naskar, K., Mohanty, S., \& Nando, G. B. (2007). Development of thin-walled halogen-free cable insulation and halogen-free fire-resistant low-smoke cable-sheathing compounds based on polyolefin elastomer and ethylene vinyl acetate blends. Journal of Applied Polymer Science, 104(5), 2839-2848. http://dx.doi.org/10.1002/app.25870

Tang, S. H., Tan, Y. J., Sapuan, S. M., Sulaiman, S., Ismail, N., \& Samin, R. (2007). The use of Taguchi method in the design of plastic injection mould for reducing warpage. Journal of Materials Processing Technology, 182(1-3), 418-426. http://dx.doi.org/10.1016/j.jmatprotec.2006.08.025 